\title{
Las estructuras financieras domésticas de las economías de APEC: bancos y mercados financieros (1980-1999)
}

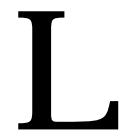
as estructuras financieras internas, es decir el conjunto de instituciones, arreglos e instrumentos que constituyen el sistema financiero de una economía de mercado, difieren ampliamente de un país a otro. Son producto de una larga evolución histórica, $\mathrm{y}$ se fueron construyendo paulatinamente, en estrecha interacción con el proceso de desarrollo económico, social y político propio de cada país o territorio. Tradicionalmente, el análisis económico ha distinguido dos grandes arquetipos: el sistema centrado en los mercados financieros y el sistema basado en la banca. El primero ha predominado históricamente en las sociedades anglo-sajonas, en particular en Gran Bretaña y en EU. En este sistema, los mercados de títulos negociables, acciones, bonos y papeles de corto plazo, desempeñan el papel fundamental, y el financiamiento empresarial de largo plazo descansa esencialmente sobre el autofinanciamiento, complementado con fondos conseguidos mediante la emisión de títulos; la participación del crédito bancario es limitada y centrada alrededor del financiamiento de corto plazo.

Por el contrario, en el sistema basado en la banca, ésta domina ampliamente el sistema financiero, y los mercados financieros son reducidos o inexistentes. El autofinanciamiento corporativo es menos importante, y las empresas recurren de manera intensiva al financiamiento bancario para financiar tanto su capital de trabajo como sus inversiones productivas. Por lo general, las relaciones bancos-empresas son estrechas, y los primeros pueden llegar a participar mayoritariamente en el capital de las segundas. Importantes contribuciones tempranas de la teoría del desarrollo (Gerschenkron, 1962, Patrick, 1966) asociaron

* Investigadora del Departamento de Estudios del Pacífico de la Universidad de Guadalajara. este modelo de financiamiento con el fenómeno del desarrollo económico tardío, específicamente con los casos de Alemania, Japón y Corea del Sur $^{1}$. En conjunto, estos arquetipos definen los extremos del rango en el cual se pueden ubicar los sistemas financieros existentes.

Más allá de esta primera diferenciación entre sistemas financieros basados respectivamente en la banca o en los mercados de títulos negociables, las estructuras financieras internas varían en función del nivel de desarrollo relativo de las economías. Así, se espera que a medida que una economía se desarrolle, su sistema financiero lo hará más que proporcionalmente, produciéndose el fenómeno de profundización financiera ${ }^{2}$; simultáneamente, las estructuras financieras se diversificarán, se crearán nuevas instituciones e instrumentos más sofisticados, hasta alcanzar el grado de complejidad presente en las economías de mercado más avanzadas. Sin embargo, este proceso no es lineal, y las particularidades de la evolución macroeconómica -en particular la presencia de inflación alta y el ritmo de crecimiento económico-, el tipo de marco legal vigente, la calidad de la impartición de justicia y el entorno político, se conjugan para estimular o frenar el desarrollo financiero, suscitando las amplias divergencias observadas en el grado de profundización y de complejidad financieras de economías con niveles de desarrollo similares ${ }^{3}$.

Estas consideraciones preliminares permiten suponer que los sistemas financieros internos de las economías de APEC diferirán ampliamente, tanto en su tamaño absoluto y relativo, como en su composición y grado de complejidad. En primer lugar debido a que los países o territorios considerados muestran obvios desniveles de tamaño e ingreso: APEC reúne desde las economías más poderosas del 
planeta, EU y Japón, hasta economías en desarrollo o en transición, pequeñas y pobres como Papua-Nueva Guinea o Vietnam.

Cabe agregar que durante las dos últimas décadas, las trayectorias de crecimiento económico han sido muy variadas, desde el ritmo muy dinámico con inflación baja de las nuevas economías industrializadas del este de Asia, hasta los desempeños relativamente pobres con inflación alta de las economías de la ribera latinoamericana de la cuenca. En segundo lugar, los contextos legales que enmarcan los sistemas financieros internos difieren en cuanto a sus orígenes (cuadro 1), pues en ciertos casos descienden de la common law británica, y en otros se originan en el código civil francés o germánico, mientras las tres economías en transición (China, Rusia y Vietnam) constituyen casos aún diferentes. Por ultimo, cabe subrayar que algunos sistemas financieros proveen servicios a escala mundial, como EU, o regional, como Hong Kong o Singapur.

Ahora bien, no obstante estas diferencias, prácticamente ninguna economía de APEC se ha quedado al margen de las reformas liberalizadoras, y en especial de los procesos de desreglamentación y de apertura financiera, que han modificado profundamente el funcionamiento de las economías y de las esferas financieras nacionales y han sustentado el proceso de globalización económica. En este sentido, y en la medida en que las reformas introducidas en el área financiera interna han buscado alcanzar los mismos objetivos generales

Cuadro 1

Orígenes de los sistemas legales de las economías de APEC

\begin{tabular}{lll}
\hline Common Law & Código civil & Código civil \\
Australia & Chile & Japón \\
Canadá & Indonesia & Corea del Sur \\
EE.UU. & México & Taiwan \\
Malasia & Filipinas & \\
Nueva-Zelanda & & \\
Singapur & & \\
\hline
\end{tabular}

Fuente: La Porta, Lopez-de-Silanes, Shleifer \& Vishny (1998). -elevación de los recursos disponibles a través del sistema, dinamización y mayor eficiencia de los intermediarios privados y en especial de los mercados, diversificación de los productos- a través de medidas esencialmente similares desreglamentación y liberalización, privatización y retracción del Estado, apertura a los inversionistas extranjeros-, podemos esperar también cierto grado de convergencia en la evolución de estos sistemas financieros internos.

Valiéndonos de una serie de indicadores, haremos en lo que sigue una presentación de los rasgos esenciales de los sistemas financieros internos de las economías de APEC, y en particular de sus instituciones centrales, los bancos y los mercados financieros ${ }^{4}$. Para ello, las economías han sido clasificadas en 3 grupos y 5 sub-grupos, que combinan nivel de ingreso, tipo de organización económica y ubicación geográfica. En una primera sección, se abordará la evolución de la profundización financiera, a través del análisis de indicadores de actividad del sistema bancario. En la segunda, se presentarán los mercados nacionales de acciones y bonos, para luego establecer comparaciones iniciales entre las estructuras financieras.

\section{Profundización financiera y bancos: $1980-2000$}

Los indicadores de "monetización" han sido utilizados desde los trabajos pioneros sobre sistema financiero y desarrollo para medir el

proceso de profundización financiera, entendido como mejoramiento de la disponibilidad y del uso de instrumentos monetarios proporcionados mayormente por el sistema bancario. Dos razones son presentadas aquí: la primera, M1/ PIB -donde el agregado monetario M1 recoge los billetes y monedas en circulación y los depósitos bancarios en cuenta corrientemide la importancia relativa de los medios de pago básicos de una 
economía de mercado en relación con el PIB; la segunda, M2/PIB, amplia el agregado monetario anterior al incluir en el numerador depósitos bancarios de corto plazo: al tomar en consideración instrumentos de ahorro, permite dar cuenta de otro tipo de servicios ofrecidos típicamente por la banca. Las cifras se presentan para cada país en los cuadros 2 y 3 , en los cuales se muestran los valores a inicio y fin del período, así como los promedios calculados para cada década.

El análisis de los cuadros permite observar que se produjo una profundización financiera en todas las economías, con la excepción notable de EU (para ambas razones), y de Corea del Sur y Singapur (en el caso de M1/ PIB); por otro lado, este proceso se ha dado por lo general en el agregado financiero más amplio, lo que nos indica que un movimiento de diversificación de los instrumentos financieros ha tenido lugar simultá-neamente. Ahora bien, ya establecida esta tendencia común, se pueden observar sustanciales diferencias en los niveles y en los ritmos de profundización mostrados por las economías.

Así, las economías asiáticas que presentaban mayores niveles de monetización a inicios del

\begin{tabular}{c}
\hline \hline Las estructuras \\
financieras internas \\
son producto de una \\
larga evolución \\
histórica, que se \\
fueron construyendo \\
paulatinamente, en \\
estrecha interacción \\
con el proceso de \\
desarrollo económico, \\
social y político \\
propio de cada país o \\
territorio \\
\hline
\end{tabular}

En el otro extremo, los menores niveles de monetización, tanto al inicio como al final del período, pertenecen a países en desarrollo y en transición: en primer lugar, las economías de la ribera occidental, luego, en Asia del sureste, Filipinas y Papua-Nueva Guinea, y finalmente las antiguas economías planificadas, con la excepción de China. En 1999, México y Rusia mostraban las razones de M2/PIB más bajas, el primero como consecuencia de la crisis bancaria iniciada en 1995 y aún no resuelta, la segunda debido al severo proceso de crisis generalizada y de desmonetización que siguió al desplome de la Unión Soviética.

Por último, si exceptuamos a Japón, las economías desarrolladas presentaban, a finales del período, niveles promedio de profundización bastante cercanos: entre 1980 y 1999 , se produjo una convergencia en sus grados de monetización, pues estos se elevaron en todas las demás economías mientras se estancaban en los EU, una evolución atribuible al cambio que se produjo en el papel de la banca, vale decir el fenómeno de desintermediación bancaria y el auge de los intermediarios de mercado, que se inició en esta economía para difundirse luego a escala mundial $^{5}$. período, Japón, Hong Kong, Singapur, Taiwán, Malasia, Tailandia y China continental, experimentaron elevados ritmos de profundización financiera y mantuvieron por lo tanto razones superiores a las demás economías, incluyendo a las de nivel de desarrollo alto. Resulta interesante subrayar que, si bien las economías mencionadas difieren en cuanto a sus niveles de desarrollo, todas gozaron, si exceptuamos a Japón, de fuertes ritmos de crecimiento económico, hecho que parece sugerir la importancia de la retroalimentación entre esta variable y la profundización financiera.
Los dos indicadores siguientes abordan otro servicio aportado por el sistema bancario: la provisión de financiamiento a la actividad económica a través del crédito La primera razón mide la importancia del crédito interno en relación con el PIB, mientras la segunda hace lo propio para el crédito al sector privado. Dentro de la visión liberalizadora, se considera que este tipo de crédito se halla más directamente relacionado con las actividades productivas $\mathrm{y}$, en consecuencia, con el crecimiento económico; a medida que el Estado 
Cuadro 2

$\mathrm{M} 1 / \mathrm{PIB}$

\begin{tabular}{|c|c|c|c|c|}
\hline ECONOMÍAS & 1980 & 1999 & $\begin{array}{l}\text { promedio } \\
1980-1989\end{array}$ & $\begin{array}{l}\text { promedio } \\
1990-1999\end{array}$ \\
\hline \multicolumn{5}{|c|}{ 1) Desarrollo alto } \\
\hline Australia & 0.122 & 0.206 & 0.109 & 0.170 \\
\hline Canadá & 0.112 & 0.209 & 0.131 & 0.177 \\
\hline EEUU & 0.175 & 0.157 & 0.174 & 0.172 \\
\hline Japón & 0.290 & 0.484 & 0.291 & 0.352 \\
\hline Nueva Zelanda & 0.110 & N/D & 0.131 & 0.273 \\
\hline
\end{tabular}

\section{2) Desarrollo medio o en desarrollo}

\section{Ribera Occidental}

\begin{tabular}{lrrrr}
\hline Chile & 0.094 & 0.108 & 0.085 & 0.091 \\
Mexico & 0.108 & 0.086 & 0.079 & 0.093 \\
$\begin{array}{l}\text { Perú } \\
\text { Ribera Oriental * }\end{array}$ & 0.086 & 0.116 & 0.075 & 0.071 \\
\hline \multicolumn{1}{c}{ 1)Asia del Este } & & & & \\
Corea del Sur & & & & \\
Hong Kong & 0.107 & 0.092 & 0.096 & 0.094 \\
Singapur & 0.145 & 0.183 & 0.172 & 0.182 \\
Taiwan & 0.250 & 0.216 & 0.239 & 0.218 \\
$\quad$ 2)Asia del Sureste & 0.272 & 0.484 & 0.389 & 0.457 \\
Brunei & & & & \\
Indonesia & $\mathrm{N} / \mathrm{D}$ & $\mathrm{N} / \mathrm{D}$ & $\mathrm{N} / \mathrm{D}$ & $\mathrm{N} / \mathrm{D}$ \\
Filipinas & 0.114 & 0.113 & 0.104 & 0.113 \\
Malasia & 0.074 & 0.132 & 0.075 & 0.097 \\
Papuasia N.Guinea & 0.199 & 0.241 & 0.190 & 0.221 \\
Tailandia & 0.107 & $\mathrm{~N} / \mathrm{D}$ & 0.103 & 0.119 \\
& 0.094 & 0.123 & 0.092 & 0.095
\end{tabular}

\section{3) En transición*}

\begin{tabular}{lrrrr} 
China & 0.271 & 0.573 & 0.343 & 0.442 \\
Rusia & N/D & 0.116 & N/D & 0.112 \\
Vietnam & N/D & 0.264 & 0.169 & 0.193 \\
\hline
\end{tabular}

* Datos disponibles desde 1982

N/D Datos no disponibles

Fuentes: ADB (economías asiáticas) y FMI (otras economías)

se retire de la esfera productiva y practique una mayor disciplina fiscal, la proporción de crédito orientado al sector privado debería elevarse.
El análisis de los cuadros 4 y 5 muestra la presencia de grandes tendencias similares a las expuestas en los párrafos anteriores: 
Cuadro 3

$\mathrm{M} 2 / \mathrm{PIB}$

\begin{tabular}{lcrrr}
\hline ECONOMÍAS & $\mathbf{1 9 8 0}$ & \multicolumn{1}{c}{$\begin{array}{c}\text { promedio } \\
\mathbf{1 9 9 9}\end{array}$} & $\begin{array}{l}\text { promedio } \\
\mathbf{1 9 8 9}\end{array}$ & $\mathbf{1 9 9 0 - 1 9 9 9}$ \\
\hline 1) Desarrollo alto & & & & \\
Australia & 0.388 & 0.706 & 0.413 & 0.620 \\
Canadá & 0.466 & 0.614 & 0.459 & 0.586 \\
EEUU & 0.629 & 0.614 & 0.677 & 0.629 \\
Japón & 0.862 & 1.257 & 0.980 & 1.140 \\
Nueva Zelanda & 0.277 & N/D & 0.300 & 0.617
\end{tabular}

\section{2) Desarrollo medio o en desarrollo}

\section{Ribera Occidental}

\begin{tabular}{lrrrr}
\hline Chile & 0.260 & 0.513 & 0.367 & 0.417 \\
Mexico & 0.291 & 0.262 & 0.249 & 0.271 \\
$\begin{array}{l}\text { Perú } \\
\text { Ribera Oriental * }\end{array}$ & 0.163 & 0.321 & 0.149 & 0.212 \\
\hline \multicolumn{1}{c}{ 1)Asia del Este } & & & & \\
Corea del Sur & & & & \\
Hong Kong & 0.366 & 0.681 & 0.362 & 0.452 \\
Singapur & 1.088 & 2.689 & 1.517 & 2.141 \\
Taiwan & 0.698 & 1.212 & 0.771 & 0.956 \\
$\quad$ 2)Asia del Sureste & 0.740 & 1.906 & 1.103 & 1.735 \\
Brunei & & & & \\
Indonesia & $\mathrm{N} / \mathrm{D}$ & $\mathrm{N} / \mathrm{D}$ & $\mathrm{N} / \mathrm{D}$ & $\mathrm{N} / \mathrm{D}$ \\
Filipinas & 0.177 & 0.584 & 0.244 & 0.487 \\
Malasia & 0.251 & 0.453 & 0.240 & 0.362 \\
Papuasia N.Guinea & 0.605 & 1.104 & 0.672 & 0.882 \\
Tailandia & 0.248 & $\mathrm{~N} / \mathrm{D}$ & 0.299 & 0.340 \\
& 0.432 & 1.035 & 0.563 & 0.833
\end{tabular}

\section{3) En transición*}

\begin{tabular}{lrrrr} 
China & 0.413 & 1.475 & 0.570 & 1.077 \\
Rusia & N/D & 0.217 & N/D & 0.202 \\
Vietnam & N/D & 0.357 & 0.195 & 0.262 \\
\hline
\end{tabular}

* Datos disponibles desde 1982

N/D Datos no disponibles

Fuentes: ADB (economías asiáticas) y FMI (otras economías)

1. Un crecimiento, por lo general muy dinámico, del crédito interno y del crédito al sector privado, con excepciones: EU, México y Papua-Nueva Guinea.
2. Niveles muy elevados para ambos indicadores, tanto al inicio como al final del período para algunas economías asiáticas: Japón, Hong Kong, Taiwán. China, Malasia y 
Cuadro 4

crédito interno/PIB

\begin{tabular}{|c|c|c|c|c|}
\hline ECONOMÍAS & 1980 & 1999 & $\begin{array}{l}\text { promedio } \\
1980-1989\end{array}$ & $\begin{array}{l}\text { promedio } \\
1990-1999\end{array}$ \\
\hline \multicolumn{5}{|c|}{ 1) Desarrollo alto } \\
\hline Australia & 0.422 & 0.927 & 0.483 & 0.819 \\
\hline Canadá & 0.510 & 0.756 & 0.526 & 0.712 \\
\hline EEUU & 0.810 & 0.827 & 0.857 & 0.814 \\
\hline Japón & 1.041 & 1.439 & 1.194 & 1.372 \\
\hline Nueva Zelanda & 0.268 & N/D & 0.301 & 0.891 \\
\hline
\end{tabular}

\section{2) Desarrollo medio o en desarrollo}

\section{Ribera Occidental}

\begin{tabular}{lrrrr}
\hline Chile & 0.446 & 0.714 & 0.862 & 0.639 \\
Mexico & 0.320 & 0.222 & 0.328 & 0.299 \\
$\begin{array}{l}\text { Perú } \\
\text { Ribera Oriental * }\end{array}$ & 0.128 & 0.284 & 0.152 & 0.172 \\
\hline \multicolumn{1}{c}{ 1)Asia del Este } & & & & \\
Corea del Sur & & & & \\
Hong Kong & 0.506 & 0.787 & 0.509 & 0.597 \\
Singapur & 0.986 & 1.408 & 0.955 & 1.394 \\
Taiwan & 0.618 & 0.837 & 0.736 & 0.681 \\
$\quad$ 2)Asia del Sureste & 0.703 & 1.603 & 0.756 & 1.467 \\
Brunei & & & & \\
Indonesia & $\mathrm{N} / \mathrm{D}$ & $\mathrm{N} / \mathrm{D}$ & $\mathrm{N} / \mathrm{D}$ & $\mathrm{N} / \mathrm{D}$ \\
Filipinas & 0.142 & 0.587 & 0.193 & 0.513 \\
Malasia & 0.508 & 0.641 & 0.342 & 0.501 \\
Papuasia N.Guinea & 0.546 & 1.004 & 0.674 & 0.862 \\
Tailandia & 0.207 & $\mathrm{~N} / \mathrm{D}$ & 0.195 & 0.249 \\
& 0.520 & 1.260 & 0.631 & 0.975 \\
3) En transición* & & & & \\
China & & & & \\
Rusia & 0.555 & 1.304 & 0.705 & 1.012 \\
Vietnam & N/D & 0.327 & $\mathrm{~N} / \mathrm{D}$ & 0.293 \\
\hline
\end{tabular}

* Datos disponibles desde 1982

N/D Datos no disponibles

Fuentes: ADB (economías asiáticas) y FMI (otras economías)

Tailandia, que inician el período con niveles relativos menores, mostraban también en 1999 razones bastante superiores a los promedios registrados en las economías desarrolladas.
3. México, Perú, en la ribera occidental, Papua-Nueva Guinea en Asia del sureste, Rusia y Vietnam presentaban en 1999 la menor capacidad para financiar las actividades económicas a través del crédito. 
4. Un proceso de convergencia en los niveles mostrados por ambas razones en las economías de mayor nivel de desarrollo, exceptuando siempre a Japón.

Algunas evoluciones particulares merecen un comentario. En primer lugar Singapur, que presentaba al igual que sus vecinos un elevado nivel de monetización, muestra razones de crédito más bajas que se acercan más a los promedios de las economías más avanzadas. Veremos en la sección siguiente que los mercados financieros desempeñan en este país un papel más relevante. En segundo lugar, las razones de crédito bancario relativamente bajas de Corea del Sur no parecen corresponder al papel desempeñado tradicionalmente por la banca, ni a los elevados niveles de endeudamiento corporativo que predominan en esta economía. Esta discrepancia se debe al crecimiento de las actividades desarrolladas por la banca a partir de los recursos provenientes de las cuentas fiduciarias, menos reglamentadas y asimiladas en las estadísticas manejadas aquí como actividades de instituciones financieras nobancarias. Si volvemos a incorporar los fondos prestados de esta manera en las actividades bancarias, las razones de crédito agregado y crédito al sector privado en relación al PIB se elevaban en 1999 a 1.4 y 1.35 respectivamente ( 1 y 0.98 en promedio entre 1990 y 1999).

En síntesis, los indicadores que acabamos de presentar muestran el proceso de crecimiento experimentado por la mayoría de los sistemas bancarios durante el período de introducción de reformas estructurales favorables al mercado. Si cierta convergencia parece producirse en el tamaño relativo de los sistemas bancarios de las economías más avanzadas, con la excepción de Japón, nada similar parece ocurrir entre las economías de ingreso medio o bajo. En particular, el grupo de economías asiáticas ya señaladas, presentan sistemas bancarios bastante más "grandes" que el promedio 6 , mientras dos economías de la ribera occidental, México y Perú, las economías en transición (exceptuando a China) y ciertas economías de Asia del Sureste como Papua-Nueva Guinea o Filipinas muestran desarrollos inferiores al promedio.
Ahora bien, estos indicadores nos señalan los tamaños de los sistemas bancarios en relación con el de las economías, pero no nos permiten comparar sus tamaños absolutos. En ausencia de datos más detallados, se puede sin embargo mencionar que los sistemas bancarios estadounidense y japonés dominan ampliamente el panorama bancario de las economías de APEC: en términos absolutos, las grandes instituciones originarias de estos dos países dominan la lista de los 10 bancos más grandes del mundo ${ }^{7}$. Veremos en la sección siguiente que estas asimetrías son aún más acentuadas en el caso de los mercados financieros.

\section{Los mercados de títulos negociables: panorama en 2000.}

En valor absoluto, los mercados de títulos negociables de las economías de APEC se hallan ampliamente dominados por las plazas estadounidenses y japonesas. En el caso de los mercados accionarios, la bolsa de Nueva York representa cerca del 54 por ciento de la capitalización total de los mercados de APEC, seguida por el mercado electrónico estadounidense Nasdaq, con 16.7 por ciento, y por la bolsa de Tokio, con 14.7 por ciento de la capitalización. Con la excepción de las bolsas canadienses (bolsas de Toronto, Montreal y Canadian Venture Exchange asociadas), ninguno de los demás mercados alcanzaba una proporción superior al 3 por ciento de la capitalización agregada en 2000 (gráfico 1).

Los mercados locales de bonos públicos y privados, que aportan financiamiento de mediano y largo plazo, muestran por su parte el predominio de las plazas japonesas (Osaka y Tokio). El valor total de los bonos registrados a fin de año en ambas plazas constituía 63.5 por ciento del valor total de mercado de las economías pertenecientes a $\mathrm{APEC}^{8}$, mientras el valor registrado en plazas estadounidenses alcanzaba 26.55 por ciento de este total, y, en el caso de Corea del Sur, 4.19 por ciento. En las dos primeras economías -y particularmente en Japón-, la enorme mayoría de los bonos registrados financian al sector gubernamental: el peso de ambos mercados está directamente 
Cuadro 5

Crédito al sector privado/PIB

\begin{tabular}{lcrrr}
\hline ECONOMÍAS & $\mathbf{1 9 8 0}$ & \multicolumn{1}{c}{$\begin{array}{c}\text { promedio } \\
\text { promedio }\end{array}$} & \multicolumn{1}{c}{$\mathbf{1 9 8 0 - 1 9 8 9}$} & $\mathbf{1 9 9 0 - 1 9 9 9}$ \\
\hline 1) Desarrollo alto & & & & \\
Australia & 0.272 & 0.872 & 0.364 & 0.736 \\
Canadá & 0.440 & 0.672 & 0.466 & 0.608 \\
EEUU & 0.663 & 0.712 & 0.707 & 0.682 \\
Japón & 0.845 & 1.152 & 0.998 & 1.176 \\
Nueva Zelanda & 0.184 & $\mathrm{~N} / \mathrm{D}$ & 0.244 & 0.897
\end{tabular}

\section{2) Desarrollo medio o en desarrollo}

\section{Ribera Occidental}

\begin{tabular}{lllll}
\hline Chile & 0.434 & 0.662 & 0.621 & 0.534 \\
Mexico & 0.193 & 0.163 & 0.147 & 0.248 \\
Perú & 0.114 & 0.264 & 0.105 & 0.166
\end{tabular}

\section{Ribera Oriental *}

1)Asia del Este

$\begin{array}{lllll}\text { Corea del Sur } & 0.466 & 0.654 & 0.464 & 0.536 \\ \text { Hong Kong } & 0.000 & 1.595 & 0.000 & 1.544 \\ \text { Singapur } & 0.666 & 0.782 & 0.686 & 0.738 \\ \text { Taiwan } & 0.564 & 1.401 & 0.692 & 1.332\end{array}$

\section{2)Asia del Sureste}

Brunei

$$
\text { N/D }
$$

N/D

N/D

N/D

Indonesia

0.133

0.211

0.208

0.496

Filipinas

0.349

0.412

0.220

0.340

Malasia

0.482

1.073

0.617

0.881

Papuasia N.Guinea

0.203

N/D

0.245

0.239

Tailandia

0.341

1.112

0.464

0.945

\section{3) En transición*}

\begin{tabular}{lrrrr} 
China & 0.556 & 1.218 & 0.697 & 0.971 \\
Rusia & N/D & 0.115 & N/D & 0.104 \\
Vietnam & N/D & 0.217 & 0.017 & 0.087 \\
\hline
\end{tabular}

* Datos disponibles desde 1982

N/D Datos no disponibles

Fuentes: ADB (economías asiáticas) y FMI (otras economías)

relacionado con la deuda pública y, en el caso de Japón, al acelerado endeudamiento contraído durante los sucesivos planes de relanzamiento de la economía aplicados durante los noventa ${ }^{9}$. En cuanto a Corea del Sur, los bonos públicos representaban a fines del 2000 alrededor de $2 / 3$ partes del valor de los bonos existentes ${ }^{10}$. Del conjunto de plazas relevantes (gráfico 2), sólo Hong Kong registraba sobretodo bonos 
extranjeros, hecho que refleja su papel de plaza financiera regional ${ }^{11}$.

Ahora bien, ¿cuál es la importancia relativa que adquieren estos mercados financieros en cada economía de APEC? Para ello se calcularon dos razones financieras que miden el tamaño relativo de ambos mercados en relación con el PIB. La razón capitalización de mercado/PIB nos informa acerca del tamaño del mercado accionario, mientras el valor de bonos/PIB hace lo propio para los mercados de títulos de deuda negociables (gráficos 3 y 4).

De las 17 economías de APEC que poseen bolsas de valores que presentan información ${ }^{12}$, cuatro tienen mercados accionarios de gran tamaño relativo: Hong Kong y Singapur, donde el valor capitalizado representaba en 2000 respectivamente 3.8 y 2.3 veces el valor del PIB, seguidos por EU y Malasia, ambos con valores de 1.8 veces el PIB. En Australia, Canadá, Chile, Taiwán y Japón, el valor total de las acciones superaba o alcanzaba el valor anual del PIB, lo cual indica también la presencia de un mercado bastante grande. Las razones calculadas para China, Indonesia, Tailandia, en Asia, y para México y Perú en América, muestran en cambio mercados más pequeños.

El desarrollo de los mercados de bonos de largo plazo es aún más restringido: de las 21 economías, sólo 14 informan de la relevancia de las transacciones realizadas con este tipo de instrumentos, de las cuales ninguna de las economías en transición ${ }^{13}$. Singapur y Japón poseen los mercados de mayor tamaño relativo para sus economías, pues representan respectivamente 2.3 y 1.2 veces el valor anual del PIB. Otros mercados de gran tamaño relativo son los de Corea del Sur y Hong Kong, con razones de 0.75 y 0.62 , Chile y EU con 0.38 y 0.26. Las cifras de Malasia, México y Perú denotan mercados incipientes.

En síntesis, los mercados financieros de APEC se hallan dominados en términos absolutos por las plazas estadounidenses y japonesas; Singapur y Hong Kong afirman su papel de plazas financieras regionales, mientras Canadá, Malasia, Corea del Sur, Taiwán y Chile poseen mercados de tamaño importante para su economía. En la sección siguiente, se presentan algunos indicadores estructurales que permitirán profundizar en el análisis comparativo de los sistemas financieros de las economías de APEC.

\section{Dos indicadores de estructura financiera}

El primer indicador que se introduce aquí (M2/ M1) mide el grado de diversificación de los instrumentos así como la importancia relativa de los instrumentos de ahorro bancario. En las etapas iniciales del desarrollo financiero, se espera un crecimiento de esta razón financiera,

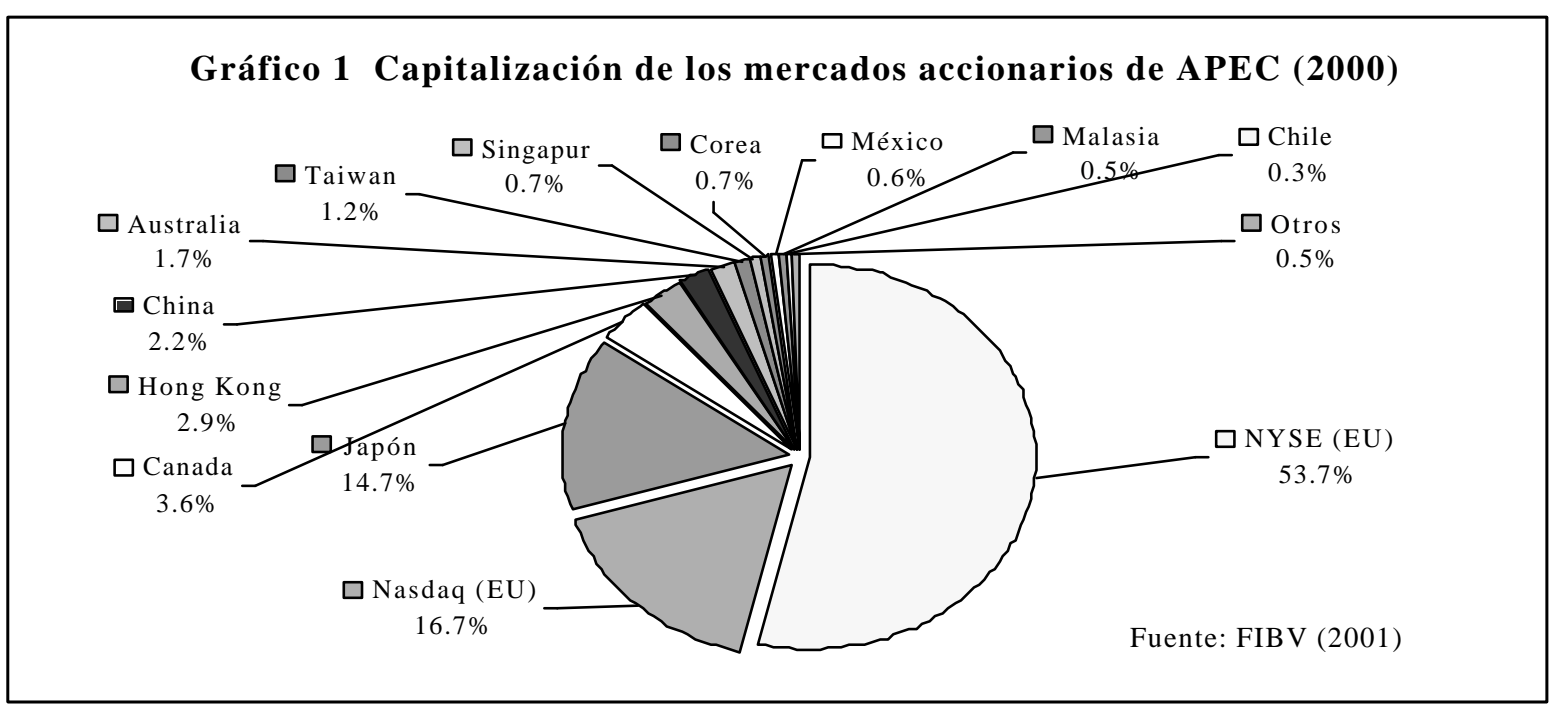



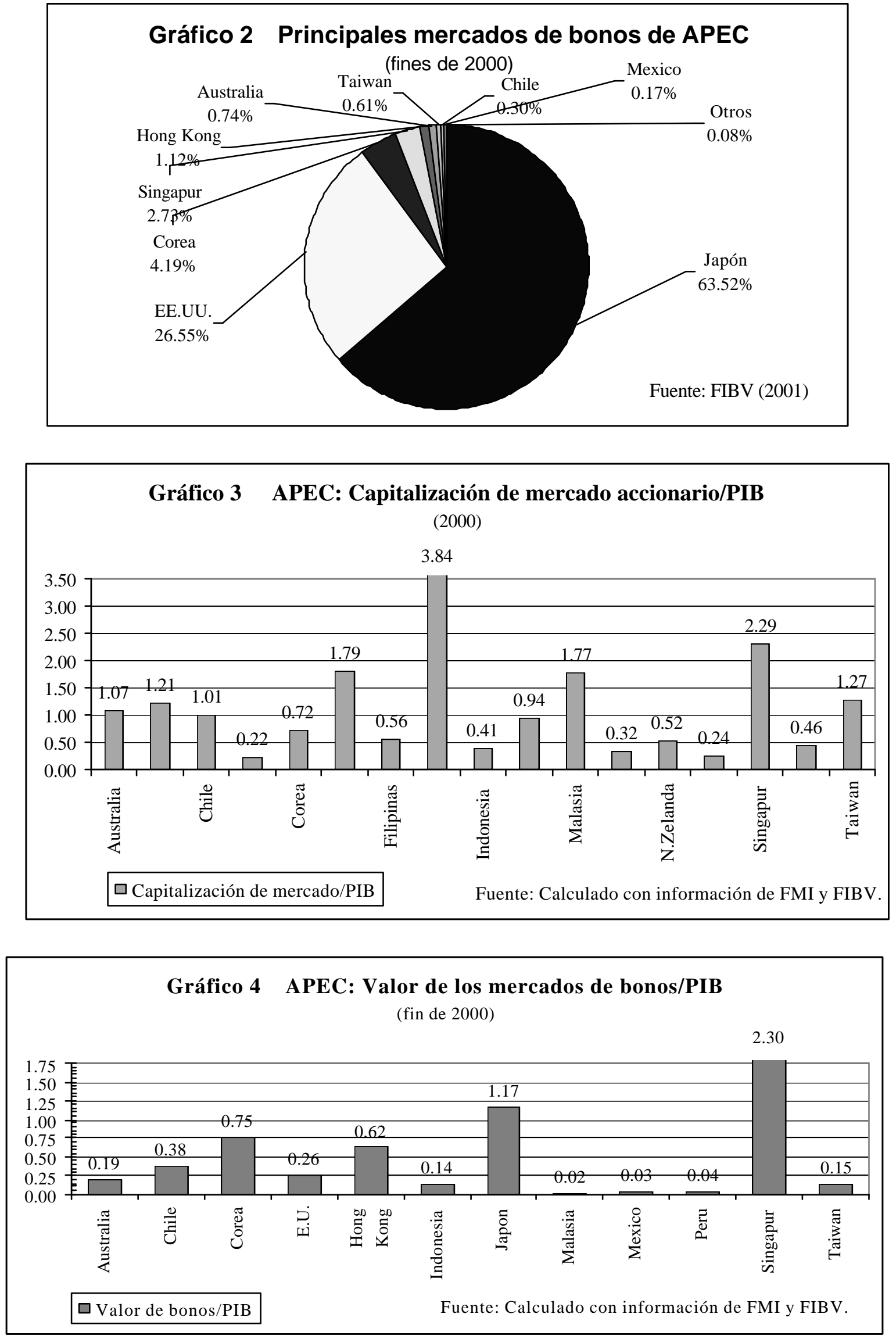
conforme el sistema bancario eleva su oferta de instrumentos y se va reduciendo el peso relativo del circulante. El segundo indicador relaciona el valor total de los instrumentos del mercado de capitales (bonos + acciones) y los instrumentos bancarios, estimado a través del agregado monetario M2. Esta razón señala el tamaño relativo de mercados y bancos, y se espera que adquiera un valor más alto en sistemas financieros donde los mercados predominan. Los valores calculados para cada economía se presentan en el cuadro $6^{14}$.

La evolución del primer indicador muestra interesantes y fuertes contrastes entre los diferentes grupos de economías. En primer lugar, cabe subrayar que los valores promedios descienden para los economías de mayor nivel de desarrollo entre 1980-89 y 1990-99, mientras que, con muy pocas excepciones, estos promedios se elevan para las demás. Estas sendas divergentes encuentran su probable explicación en el proceso de desintermediación bancaria en curso en el conjunto de economías más avanzadas, asociado al surgimiento de nuevos instrumentos e intermediarios, como los fondos de inversión; mientras tanto, el desarrollo financiero de las demás economías ha seguido la vía bancaria más "tradicional” . En segundo lugar, los valores más altos de este indicador se concentran en las economías asiáticas de mayor crecimiento -Hong Kong, Tailandia, Corea del Sur, Singapur, Indonesia, Malasia y Taiwán- a las cuales se suma Chile. En todos estos casos, los valores del indicador superan ampliamente los niveles alcanzados en las economías de mayor nivel de desarrollo. Finalmente, los niveles más bajos de diversificación se encuentran, sin mayor sorpresa, en los sistemas bancarios de menor tamaño -México, Perú, Papua-Nueva Guinea, Rusia y Vietnam, a los cuales se agrega China; aún cuando, como lo hemos visto, esta economía presenta altos niveles de profundización financiera, los instrumentos utilizados son todavía rudimentarios y poco diversificados -si bien se produjo un proceso de recuperación (catching-up), como lo señala la tasa de crecimiento del indicador más alta que en los demás casos.
La lectura de los valores del segundo indicador permite clasificar a Singapur y a EE.UU. como las economías donde los instrumentos negociables desempeñan el papel más destacado en relación con los instrumentos bancarios tradicionales, pues representan respectivamente 3.8 y 3.3 veces el valor de M2. Chile, Corea del Sur, Canadá, Australia, Japón, Hong Kong y Malasia poseen igualmente mercados de gran tamaño en relación con su sistema bancario, pues su valor agregado oscila entre 1.7 y 2.8 veces el valor de M2. En contraste, los valores más bajos del indicador se hallaban en Tailandia y China.

\section{Comentarios finales}

Fundamentándonos en los tres diferentes grupos de indicadores comentados en este trabajo, proponemos una clasificación inicial de las estructuras financieras de las economías de $\mathrm{APEC}^{15}$. El cuadro resultante combina la información relativa a bancos y mercados y permite establecer diferentes tipos de estructuras financieras, desde economías que poseen bancos y mercados de gran tamaño hasta economías donde ambos tipos de instituciones son pequeñas (cuadro 7).

Resulta también interesante cruzar la información de los cuadros 7 y l, combinándola con datos de crecimiento económico. Ello permite subrayar en primer lugar que las economías que poseen mercados y/o bancos de gran tamaño comparten orígenes legales británicos (EU, Hong Kong y Singapur, en el caso de los mercados, Hong Kong, Singapur, Malasia, Tailandia, Nueva-Zelanda, para los bancos) o germánicas (Japón, Taiwán y Corea del Sur). Por su parte, China es la única economía en transición que posee un sistema bancario muy grande. Finalmente, las economías que combinan sistemas bancarios y mercados poco desarrollados pertenecen al ámbito del código civil francés (México, Perú, Filipinas, Indonesia) o son economías en transición (Rusia y Vietnam).

Ahora bien, resultaría en extremo simplista atribuir estas características 
Cuadro 6

INDICADORES DE ESTRUCTURA FINANCIERA

\begin{tabular}{|c|c|c|c|c|c|}
\hline \multirow{3}{*}{ ECONOMÍAS } & \multicolumn{4}{|c|}{ RAZÓN M2/M1 } & \multirow{2}{*}{$\begin{array}{l}\text { RAZÓN valor } \\
\text { Mercados/M2 }\end{array}$} \\
\hline & \multicolumn{3}{|c|}{ promedio } & promedio & \\
\hline & 1980 & 1999 & 1980-1989 & 1990-1999 & 1999 \\
\hline \multicolumn{6}{|c|}{ 1) Desarrollo alto } \\
\hline Australia & 3.165 & 3.422 & 3.814 & 3.719 & 1.79 \\
\hline Canadá & 4.166 & 2.941 & 3.617 & 3.333 & 1.98 \\
\hline EEUU & 3.602 & 3.907 & 3.899 & 3.676 & 3.33 \\
\hline Japón & 2.975 & 2.600 & 3.368 & 3.323 & 1.68 \\
\hline Nueva Zelanda & 2.510 & N/D & 2.639 & 2.265 & 0.88 \\
\hline
\end{tabular}

2) Desarrollo medio o en desarrollo

Ribera Occidental

\begin{tabular}{lrrrrr} 
Chile & 2.766 & 4.749 & 4.380 & 4.594 & 2.81 \\
Mexico & 2.703 & 3.035 & 3.134 & 2.998 & 1.33 \\
$\begin{array}{l}\text { Perú } \\
\text { Ribera Oriental * }\end{array}$ & 1.748 & N/D & 2.012 & 2.697 & 0.81 \\
\hline \multicolumn{1}{c}{ 1)Asia del Este } & & & & & \\
Corea del Sur & & & & & \\
Hong Kong & 3.432 & 7.421 & 3.770 & 4.901 & 2.16 \\
Singapur & 7.520 & 14.717 & 8.779 & 11.888 & 1.66 \\
Taiwan & 2.796 & 5.608 & 3.226 & 4.414 & 3.79 \\
$\quad$ 2)Asia del Sureste & 2.717 & 3.937 & 2.888 & 3.803 & 0.74 \\
Indonesia & & & & & \\
Filipinas & 1.555 & 5.185 & 2.344 & 4.340 & 0.70 \\
Malasia & 3.375 & 3.445 & 3.239 & 3.726 & 1.23 \\
Papuasia N.Guinea & 3.038 & 4.576 & 3.547 & 4.002 & 1.63 \\
Tailandia & 2.316 & 2.334 & 2.907 & 2.805 & N/D \\
Brunei & 4.611 & 8.443 & 6.121 & 8.782 & 0.44 \\
& N/D & N/D & N/D & N/D & N/D
\end{tabular}

\section{3) En transición*}

\begin{tabular}{llllll} 
China & 1.52 & 2.58 & 1.66 & 2.43 & 0.22 \\
Rusia & N/D & 1.87 & N/D & 1.81 & N/D \\
Vietnam & N/D & 1.35 & 1.15 & 1.37 & N/D \\
\hline
\end{tabular}

* Datos disponibles desde 1982

N/D Datos no disponibles

Fuentes: ADB (economías asiáticas) y FMI (otras economías);

FIBV (estadísticas de mercados financieros) 


\begin{tabular}{|l|l|l|l|}
\hline $\begin{array}{l}\text { Sistema } \\
\text { Bancario }\end{array}$ & $\begin{array}{l}\text { Mercados } \\
\text { Financieros }\end{array}$ & Grandes & Medianos \\
\hline Grande & $\begin{array}{l}\text { Japón } \\
\text { Hong Kong } \\
\text { Singapur }\end{array}$ & $\begin{array}{l}\text { Malasia } \\
\text { Taiwan } \\
\text { Corea del Sur }\end{array}$ & $\begin{array}{l}\text { Tailandia } \\
\text { China } \\
\text { Nueva-Zelanda }\end{array}$ \\
\hline Mediano & EE.UU. & $\begin{array}{l}\text { Australia } \\
\text { Chile } \\
\text { Canadá }\end{array}$ & Indonesia \\
\hline Pequeño & & & $\begin{array}{l}\text { México } \\
\text { Perú } \\
\text { Filipinas } \\
\text { Papua-N. Guin. } \\
\text { Rusia } \\
\text { Viet-Nam }\end{array}$ \\
\hline
\end{tabular}

financieras únicamente al marco legal de los sistemas. Así, cabe subrayar que, con la excepción de Nueva-Zelanda, todas las economías que poseen un sistema bancario de gran tamaño pertenecen geográficamente a Asia del este y del sureste, y comparten elementos importantes de su estrategia de desarrollo. Ello sugiere la influencia del patrón de financiamiento "asiático", o "modelo de alto endeudamiento corporativo" (Wade \& Veneroso, 2000 ), cuya vigencia no habría sido alterada por las reformas financieras. Por otro lado, estas economías han experimentado a lo largo del período considerado tasas de crecimiento muy superiores al promedio -con la excepción de Japón. Los mayores niveles de crecimiento económico y de ahorro interno y la expansión del sistema financiero podrían haberse reforzado mutuamente, tal como lo plantean los enfoques teóricos del desarrollo financiero.

Por último, cabe agregar algunas consideraciones finales acerca de la esperada convergencia de las estructuras financieras de tan distintas economías. $\mathrm{Al}$ respecto, hemos visto que ciertos patrones presentes en la trayectoria de los sistemas financieros de las economías de mayor nivel de desarrollo parecen indicar la existencia de un proceso de convergencia. Por otro lado, existen muy pocos indicios que sugieren que este fenómeno tenga lugar entre las demás economías: las naciones y territorios asiáticos siguen mostrando un nivel de bancarización bastante más elevado que el promedio, y los demás países no parecen estar superando la brecha inicial, exceptuando tal vez el caso de los mercados de títulos negociables. En este sentido Chile constituye una excepción, pues es la única economía de América Latina que logra superar el rezago financiero; el hecho de que este país haya aplicado sus reformas estructurales con mucha anterioridad podría sugerir que estas medidas sí pueden llevar a cierta convergencia en las estructuras financieras, pero en un plazo bastante más largo de lo planteado inicialmente.

\section{Notas}

1 Las bondades y debilidades respectivas de ambos tipos de sistemas, su capacidad relativa a impulsar el crecimiento económico a través de la canalización de un mayor financiamiento, de la selección de los mejores proyectos y de la reducción del riesgo y de la incertidumbre, han sido objeto de un extenso debate, ampliado y renovado de manera reciente con nuevos trabajos que incorporan las consideraciones relativas al marco legal de la actividad financiera y el enfoque de los servicios financieros (véase Levine, 1997, 2000). Este debate no se abordará en el presente texto, pues se encuentra más allá de sus objetivos 
2 Este concepto ha sido acuñado por E. Shaw (1973).

3 El proyecto de investigación del sistema financiero doméstico del Banco Mundial ha producido una base de datos así como numerosos documentos de trabajo al respecto durante los últimos años, véase por ejemplo Demirguc-Kunt \& Levine, 1999, que establece comparaciones entre sistemas basados respectivamente sobre la banca y sobre los mercados financieros.

4 En ausencia de datos homogéneos para las economías consideradas, no abordaremos formalmente el tema de los intermediarios financieros no-bancarios, ni el de los inversionistas institucionales,a pesar de que éstos desempeñan un papel importante en varias de ellas, incluidas las más desarrolladas.

5 Véase Marchini, 2000, para una presentación sucinta de la evolución del sistema financiero estadounidense.

6 Si bien estos sistemas bancarios presentan un tamaño relativo superior al promedio, la asignación de recursos que realizan y su eficiencia han sido con frecuencia de calidad sub-estándar. Este problema ha sido una de las causas de la crisis asiática, y no está plenamente resuelto en la actualidad.

7 A ello cabe agregar el papel desempeñado por grandes bancos internacionales que han creado y se encuentran consolidando redes en ciertas regiones de APEC, como el HSBC en Asia o los bancos españoles en la ribera occidental de la cuenca.

8 Los datos que se utilizaron provienen de la información proporcionada por la FIBV, recopilada a su vez a partir de bolsas que pertenecen a esta organización. Puede dejar de lado informaciones de plazas no-miembros, y debe por lo tanto tomarse a título indicativo.

9 La primacía de los mercados de títulos públicos nos recuerda asimismo el papel pionero éstos que desempeñaron en el desarrollo de los mercados financieros globales, desde inicios de los 80 .

10 En Australia, Indonesia y Taiwán, los títulos públicos predominan nítidamente, mientras en México ý Chile existe un balance en el valor de títulos privados y públicos; finalmente, en Perú y Malasia los mercados tratan casi exclusivamente deudas privadas.

11 La información proporcionada por la base de datos de la FIBV sobre Singapur, la otra plaza financiera de alcance regional, no permite desagregar bonos nacionales o extranjeros, públicos o privados.

12 No disponemos de información sobre Brunei, PapuaNueva Guinea, Rusia y Vietnam. Sin embargo, Rusia posee un mercado accionario y resulta probable que Vietnam tenga un mercado incipiente.

13 Nueva-Zelanda y Tailandia no reportan información para el año 2000; Brunei, Filipinas, Papua-Nueva Guinea, en Asia del Sureste, y las tres economías en transición no reportan la presencia de un mercado organizado en forma de bolsa, aún cuando los gobiernos de China y Rusia emiten este tipo de instrumento.
14 Los cuadros muestran la evolución de la razón M2/M1 entre 1980 y 1999, mientras que sólo se ha calculado la razón Valor de instrumentos de mercado/M2 para el año 1999, debido a restricciones en los datos disponibles.

15 En consecuencia, esta clasificación solo toma en cuenta las consideraciones relativas al tamaño de los bancos y mercados

\section{Fuentes}

Demirgüç-Kunt, Asli \& Ross Levine (1999) : « Bank-based and Market-based Financial Systems : Cross-country Comparisons», World Bank Working Paper, Washington, junio; Gerschenkron, Alexander (1962): Economic Backwardness in Historical Perspective - A Book of Essays, Cambridge, Harvard U. Press; La Porta, Rafael, Florencio Lopez-de-Silanes, Andrei Shleifer \& Robert W. Vishny (1998) : "Law and Finance", The Journal of Political Economy, vol. 106, n ${ }^{\circ}$ 6, dic., Chicago, pp. 1113-1155; Levine Ross (1997): "Financial Development and Economic Growth: Views and Agenda", Journal of Economic Literature, vol. XXXV, junio, pp. 688-726; Levine, Ross (2000): "Bank-based or Market-based Financial Systems: which is better?" IBRD Working Paper (2000); Lynch, David (1996): "Measuring Financial Sector Development: a Study of selected Asia-Pacific Countries", The Developing Economies, Vol. XXXIV, n ${ }^{\circ} 1$, marzo, pp. 3-33; Marchini, Geneviéve (2000): "Notas sobre el sistema financiero de EE.UU., su papel internacional y su problemática actual”, en México y la Cuenca del Pacífico, vol. 3, n. 9, enero-abril, pp.26-36; Patrick, Hugh (1966): "Financial Development and Economic Growth in underdeveloped Countries", in Economic Development and Social Change, vol. 14 n. 2, enero, pp. 174-89; Shaw, Edward S (1973): Financial Deepening in Economic Development, Oxford University Press, New York; Wade, Robert \& Frank Veneroso (1998) : "The Asian Crisis : the High Debt Model vs. The Wall StreetTreasury-IMF Complex", Working Paper $\mathrm{n}^{\circ}$ 128, Russell Sage Foundation, marzo, http://www.russelsage.

\section{Información estadística:}

Banco Asiático de Desarrollo : información en línea, en http://www.adb.org/Documents/Books/Key_Indicators/ 2001/default.asp, para las economías asiáticas.

Fondo Monetario Internacional, Estadísticas financieras internacionales, para las demás economías.

Federación Internacional de Bolsas de Valores (FIBV) : información en línea en. http://www.fibv.com, para los datos relativos a los mercados financieros. 